\title{
Wind Power Forecasting and Integration to Power Grids
}

\author{
Jin Zhong, Member, IEEE, Yunhe Hou, Member, IEEE, , Felix F. Wu, Fellow, IEEE
}

\begin{abstract}
This is a summary of the presentation in the special session: "Digital Signal Processing for Green Power Systems and Delivery". In recent years, wind power penetration level in power systems has increased significantly. Grid integration has become one of the major issues for wind power growth due to the intermittent characteristics of wind power. The uncertainty of power generation from wind farms may result in power system stability and security problems. Accurate wind power forecasting could reduce the uncertainty to generation scheduling to certain extent, hence increase the wind power penetration level in the system.
\end{abstract}

Index Terms - Wind power, Wind power forecasting, power grids

\section{INTRODUCTION}

$\mathrm{W}$ orldwide environmental concern, particularly global warming, has prompted the repaid growth of renewable resources, such as wind and solar, into the electric power generation system. In North America, an additional 8,500MW of new wind capacity has been installed during 2008 resulting in total installed wind capacity to more than 26,200 MW[1]. Furthermore, the US has set a target of $20 \%$ of its power generation coming from wind by 2030 . As pioneers, significant wind power resources are integrated into European power grids and more wind power resources are planned. For instance, until 2008, wind power capacities in Denmark, Spain and Ireland are $3.1 \mathrm{GW}, 16.74 \mathrm{GW}$ and $1.0 \mathrm{GW}$ associated with, respectively, $200 \%, 90.5 \%$ and $15 \%$, maximum penetrations (wind power capacity/minimum demand) [2]. German intends to increase a national target for renewable energies of $30 \%$ by 2020 [3]. China also supports the endeavor for renewable resources and requires that any investment in new fossil-fuel generator should simultaneously put a proportional percentage into renewable source generation [4]. This tendency implies the critical need to integrate wind power into the current power systems, which is mainly designed for large fossil fuel, hydro and nuclear generating units[5].

As energy resource with significant different from traditional ones, wind power's integration leads to some critical challenges from the point of view of the electricity system. The major

The work is supported by Research Grant Council, Hong Kong SAR, under grants $717907 \mathrm{E}$ and $718608 \mathrm{E}$.

Ji Zhong, Yunhe Hou and Felix Wu are with the Department of Electrical and Electronic Engineering, The University of Hong Kong, Hong Kong, China (e-mail: jzhong@eee.hku.hk, yhhou@eee.hku.hk ffwu@eee.hku.hk). challenges come from the non-dispatchable property of wind power associated with variability and uncertainty. The variability due to the changing wind resource For example, the total wind power distribution in Spain from 2001 to 2005 shows that $50 \%$ of the time below $27 \%$ and $50 \%$ of time above $27 \%$ of wind capacity. This characteristic is definitely different from the conventional generation units associated with a very small force outage rate [6]. Meanwhile, uncertainty related to inability to predict the weather and wind. Fig. 1 illustrates an example of the performance of Numerical Weather Prediction (NWP) based physical prediction method compared to time series method for a horizon larger than a few hours ahead [7]. No matter what methods are employed so far, the errors of predictions can not be ignored.

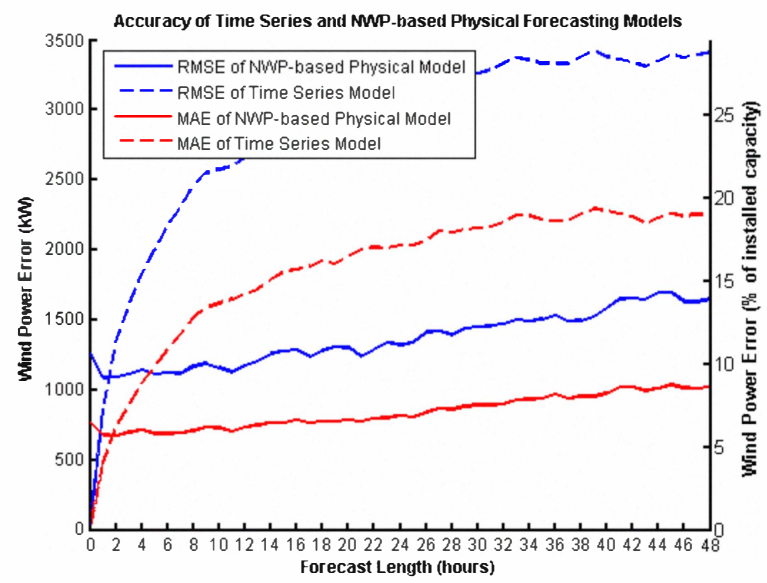

Fig. 1 Performance of different prediction methods

As one of the most fundamental issues of wind power integration, the accuracy of wind power forecasting is directly tied to the need for balancing energy and maintaining system security. In recent years, researchers have made significant efforts on wind power forecasting, and large numbers of methods are established. Generally, state-of-the-art wind power forecasting methodology is established on statistical models [8-17], physics-based methods [18-28], or their combination[1, $5,7,13,29-32]$. As a topical stochastic process, more sophisticated methods have been proposing for the purpose of accurate wind power forecasting. The objective of this paper is to present the development of state-of-the-art techniques in this area.

\section{WIND POWER FORECASTING}

Today's wind power forecasting tools are typically established on a combination of physics-based and statistical models. Generally, for a wind power forecasting tool, the 
objective is to predict mainly wind speed and direction. The typical input vectors include:

- Available meteorological forecasts up to a certain number of hours or several days

- Historical data of wind power production and weather variables. Depending on the time horizon of the forecast data, from minute data to hourly data might be needed.

Usually, the results are:

- Minute or hourly wind power forecast of a single park, group of parks or a larger area.

- Probabilistic output with confidence intervals.

Currently, physics-based models are referred to as numerical weather prediction (NWP), which is the first step of wind forecasting. These models based on meteorological observations and measurements all over the globe. According to from physical laws, a set of equations are derived. With the data come from meteorologists, weather stations, satellites, etc, the behavior of atmosphere of this planet can be calculated [19, 20,33 ]. As an analytical method, training based on historical data is unnecessary. In theory, under a set of conditions, an NWP models can predict an event by super-computers, even it never happened. However, as a typically nonlinear system, the complexity of such a calculation requires a huge computational cost and, thereby, cannot be accomplished within reasonable time. Furthermore, the knowledge of the initial state of the atmosphere is incomplete[34]. As a result, even if the equations could be solved mathematically within limited computational time, the solution may not be accurate.

Different from the NWP models, statistical models focus on empirical relationships between historical data and forecast variables. Since statistical models learn from experience, the explicit knowledge of the underlying relationship is unnecessary. Sophisticated method based on time series algorithms [10, 11, 35-39], artificial neural networks[9, 17, 18, $20,31,37,38,40,41]$, support vector machines, Kalman Filters[42], and similar technologies have been employed. The values from NWP models and measured data from the wind plant to predict the wind speed, wind-power output, and so on. Due to the capability of "learning from experience", the statistical models can account for the local terrain and other details that can't realistically be represented in the NWP models [1]. For the same reason, statistical models tend to predict typical events better than rare events. The framework for a combination wind power forecasting is illustrated in Fig. 2.

From the practical point of view, different data sources and forecasting techniques varies significantly with the time scope of forecasting. Generally, by exploiting recent data from wind plant or nearby location, statistical models are typically used for the short term forecasting, i.e., from zero to few hours. While NWP models results tend to have large error for the very short horizons. This is due to the fact that the data acquisition is not instantaneous, does not cover the full areas of the NWP models, and is too sparse to allow a perfect description of the atmospheres initial state. The longer-term forecasts will depend much more heavily on the NWP models. Since for long-term, when most data is available, the model, typically set up to cover the whole globe or at least a quarter of it, runs for another two hours or so, which means that the newest and most accurate results of the NWP model are based on a four hour old snapshot of the atmosphere. The accuracy of a NWP model is typically best after 36 hours[7]. After about six to 10 days, the skill of NWP models is typically less than that of a climatology forecast, which uses the long-term average by season and time of day[1].

Typically, the accuracy of next day hour-by-hour power forecasts using current state-of-the-art methods will have a mean absolute error (MAE) of perhaps $10-15 \%$ of the rated (nameplate) capacity of the wind plant. While, for the next few hours can typically with MAEs on the order of $5 \%$ of rated wind plant capacity. Notably, the accuracy of energy forecasts, for example total wind energy for tomorrow, can be

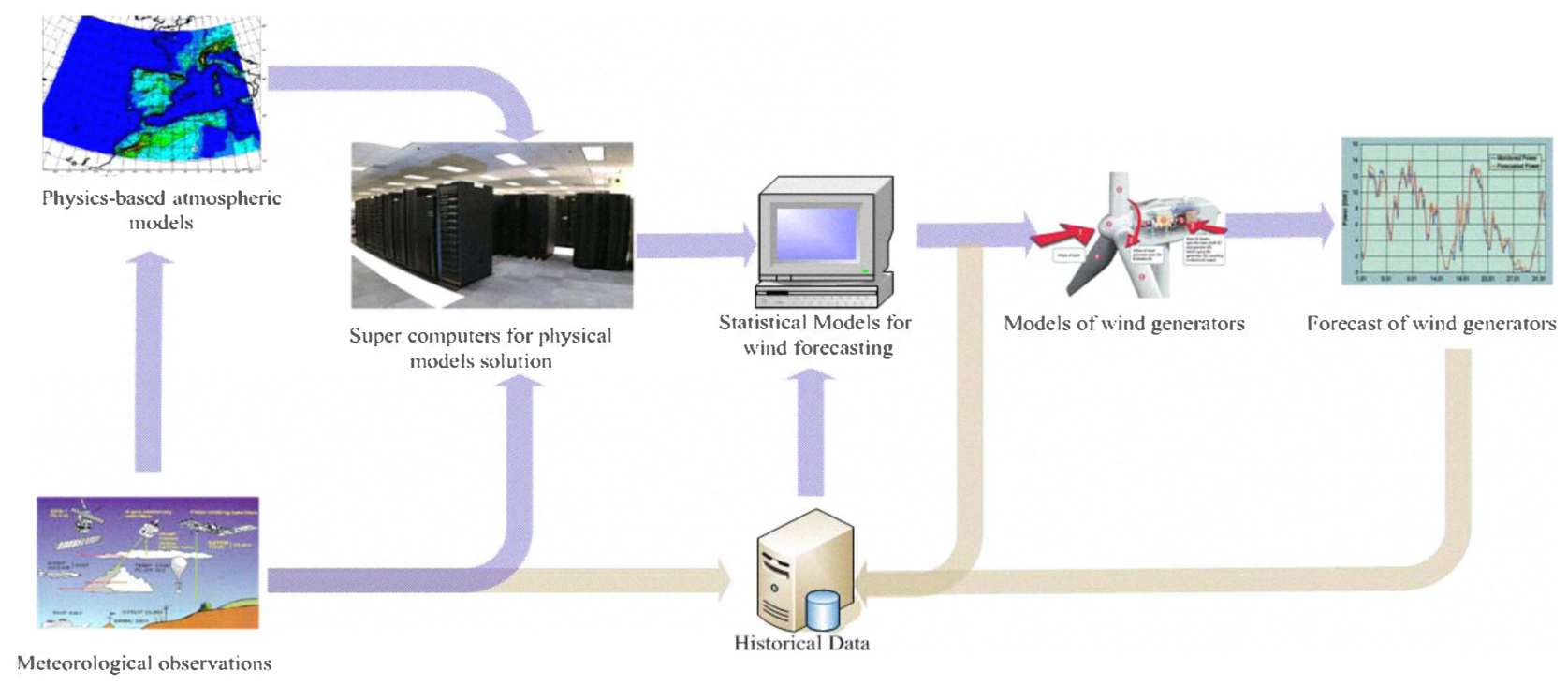

Fig. 2 Wind power forecasting by a combination method

basic approach for the utilization of statistical models is use 
significantly better than the accuracy of power forecasts. These errors tend to balance out over longer periods of time so the accuracy of energy forecasting can be quite good. In addition, forecasting errors are significantly reduced when aggregated on a system wide basis. Due to the smoothing effects of geographic dispersion, system wide forecasting errors for multiple dispersed wind plants may be reduced by perhaps $30-50 \%$ when compared with the errors of individual wind plants[32].

\section{ERRORS WIND POWER FORECASTING}

Notably, the error of wind power forecasting is unavoidable and, therefore, in addition to the forecast values, the prediction tool should provide a prediction of the uncertainty of this forecast.

\section{A. Criteria of error measurements}

No prediction model forecasts perfectly. To evaluate the performance of a prediction model, criterion or measurement is essential. Following criteria are widely used.

(1) Mean absolute error (MAE)

$$
\text { MAE }=\frac{1}{N} \sum_{i=1}^{N}\left|\varepsilon_{i}\right|
$$

where $N$ is the number of measurements, $\varepsilon_{i}=R_{i}-P_{i}$ is the error of prediction $P_{i}$ relative to the target value $R_{i}$ at time $i$.

(2) Total probabilistic prediction error (TPPE)

Two TPPEs upward one $\left(\mathrm{TPPE}_{u}\right)$ and downward one $\left(\mathrm{TPPE}_{d}\right.$ ) can be defined as follows:

$$
\begin{aligned}
\mathrm{TPPE}_{u} & =\int_{-\infty}^{+\infty} \max (P-R, 0) \cdot f_{p}(R) \cdot d R \\
\mathrm{TPPE}_{d} & =\int_{-\infty}^{+\infty} \max (R-P, 0) \cdot f_{p}(R) \cdot d R
\end{aligned}
$$

where $f_{p}(R)$ is the density function of prediction, $R$ is the target value of prediction.

$\mathrm{TPPE}_{u}$ describes the expected value of prediction over real data, and $\mathrm{TPPE}_{d}$ describes the expected value of prediction under real data.

(3) Square error (MSE)

$$
\mathrm{SE}=\frac{1}{N} \sum_{i=1}^{N} \frac{1}{2} \varepsilon_{i}^{2}
$$

This is a classical criterion, which is the similar as MAE.

(4) Error Entropy (EE)

$$
\mathrm{EE}=\frac{1}{N^{2}} \sum_{i=1}^{N} \sum_{i=1}^{N} G\left(\varepsilon_{i}-\varepsilon_{j}, 2 \sigma^{2} \mathbf{I}\right)
$$

where $G$ is a Gaussian function with a variance given by a value represented by $2 \sigma^{2}, \sigma^{2} \mathbf{I}$ is the covariance matrix.

(5) Correntropy (CC)

$$
\mathrm{EE}=\frac{1}{N} \sum_{i=1}^{N} G\left(\varepsilon_{i}, \sigma^{2} \mathbf{I}\right)
$$

(6) Error entropy with fiducial points (EEF)

$$
\mathrm{EEF}=\gamma \frac{1}{N} \sum_{i=1}^{N} G\left(\varepsilon_{i}, \sigma^{2} \mathbf{I}\right)+(1-\gamma) \frac{1}{N^{2}} \sum_{i=1}^{N} \sum_{i=1}^{N} G\left(\varepsilon_{i}-\varepsilon_{j}, 2 \sigma^{2} \mathbf{I}\right)
$$

Obviously, a good forecast is with minimal MAE, TPPE and MSE and, furthermore, it can be proved that maximal EE, CC and EEF imply the good performance of a forecasting tool [9].

\section{B. Distribution of prediction errors}

Most of researches of this area focus on the algorithms to improve the accuracy of a forecast. Some criteria are selected to evaluate the proposed method. Few researches address the problem of the distribution of prediction error, which tied directly with the problem of system reserve and storage system dispatch.

The autoregressive or related time series models are widely used in wind modeling, and large numbers of sophisticated algorithms are designed based on these models. Usually, these models presuppose the errors subject to the normal distribution. For a large geographic scope, due to the statistical compensation of combined errors, it is definitely acceptable. However, for a small area with a short time interval, empirical data show that the wind power distribution is fat-tailed and nonsymmetrical $[9,11,43]$. Models based on errors with normal distribution will not easy to model these characteristics.

To cover these essential characteristics of wind power, a convenient option is modeled the error by the conditional Gaussian distributions. The method proposed in [43] is to transform well-behaved Gaussian distributions of the forecast error of the wind speed into non-Gaussian distributions.

$$
\begin{aligned}
\operatorname{pdf}\left[P\left(u_{m}\right), P\left(u_{p}\right)\right] & =\operatorname{pdf}\left[P\left(u_{m}\right) \mid P\left(u_{p}\right)\right] \cdot \operatorname{pdf}\left[P\left(u_{p}\right)\right] \\
& =\left.\left.\operatorname{pdf}\left(u_{m} \mid u_{p}\right) \cdot \operatorname{pdf}\left(u_{p}\right) \cdot \frac{d P}{d u}\right|_{u_{m}} ^{-1} \cdot \frac{d P}{d u}\right|_{u_{p}} ^{-1}
\end{aligned}
$$

where $u_{p}$ is the predicted wind speed, $u_{m}$ is the measured values of wind speed, $\operatorname{pdf}\left(u_{p}\right)$ is the unconditional wind speed distribution (the Weibull distribution is used in [43]), $\operatorname{pdf}\left(u_{m} \mid u_{p}\right)$ is the conditional probability density function calculated by

$$
\operatorname{pdf}\left(u_{m} \mid u_{p}\right)=\frac{\operatorname{pdf}\left(u_{m}, u_{p}\right)}{\operatorname{pdf}\left(u_{p}\right)}
$$

where $\operatorname{pdf}\left(u_{m}, u_{p}\right)$ is the joint distribution assumed as a normal distribution.

A more straightforward wind power prediction error model is given by a Beta distribution as follows $[11,16]$ :

$$
\begin{gathered}
\operatorname{pdf}(P)=\frac{P^{\alpha-1} \cdot(1-P)^{\beta-1}}{B(\alpha, \beta)} \\
B(\alpha, \beta)=\int_{0}^{1} P^{\alpha-1} \cdot(1-P)^{\beta-1} d P
\end{gathered}
$$

where $\alpha$ and $\beta$ are parameters.

Fig. 3 illustrates the probability density function of Beta distribution with different parameters. The major reason for selection of Beta distribution is its variable kurtosis, which make is suitable for the fat-tailed data.

where $\gamma$ is a weighting constant between 0 and 1 . 


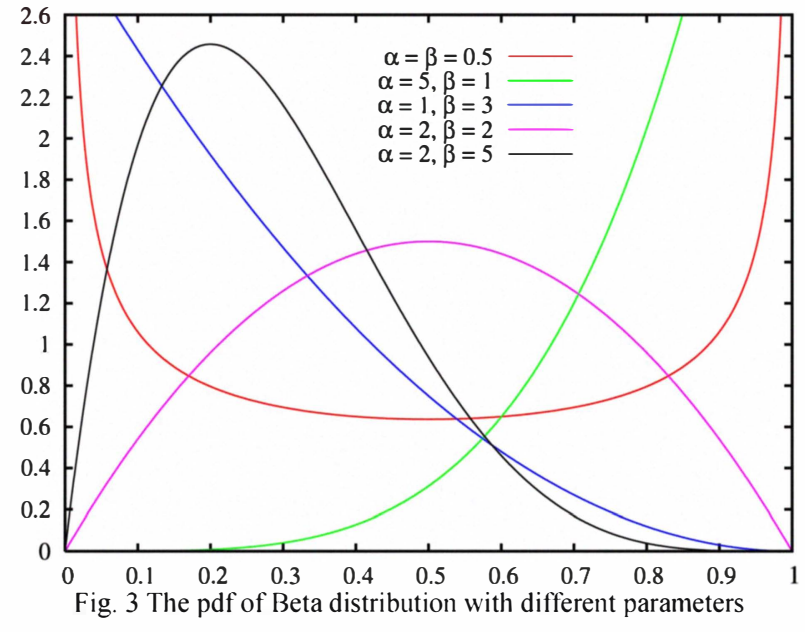

IV. APPLICATIONS OF WIND POWER FORECASTING

The objectives of a wind power forecast depend on the application and, therefore appropriate methods are selected. At present, the most important application for wind power forecasting is to evaluate energy and reserve of a power system, an essential issue for system operation. Another application is to provide forecasting of wind power feed-in for power system operation and system security assessment. Due to the location of wind farms are often far from the load center, wind power forecasting precision will significantly affect congestion caused by physical flows.

Generally, different technologies for wind power forecasting are established based on the purposes of applications. From the point of view of the power systems, following applications are critical:

- Optimal generation schedule requires wind generation forecasting of the whole control area. For this objective, the time horizon will be determined by the types of conventional generating units, as well as the trading gate closure times. Unit commitment for systems with significant wind penetration is one of the hot topic in this areas [12, 35, 44-48].

- To determine reserve power and energy, an accurate wind power forecasting is critical[48-51]. To accomplish this issue, the net forecasting errors associated with wind power and demand should be minimized. The difficulties lie in the relative error on wind production forecast is usually larger than the error on the load forecast. Furthermore, the standard deviation of this error increases with the prediction horizon[52].

- For the purpose of security management, such as grid operation and congestion management, the forecast wind power generation in each grid area or grid connection point is needed. For this purpose, a forecast for small region or a single wind farm is required.

To cover the requirements of application, generally, current wind power forecasting tools may be classified into a couple of groups. According to the scope of the forecasting, following three kinds of forecasting are implemented.

- Single park forecasting
- Multi-park forecasting

- Wide area forecasting

Usually, geographic dispersion increases relative forecasting errors decrease as a consequence of statistical compensation of combined errors.

On the other hand, according to the time horizon, other three kinds of forecasting are used, they are

- Long term forecast. Normally used to estimate wind power energy outcome during long periods of time.

- Short term forecast 1 hour to several days.

- Very short term forecast $<1$ hour.

\section{CONCLUSION}

For the purpose of establishment of green power systems and delivery, power systems have been undergoing fundamental changes. During this process, with significant wind power generation penetration into power systems, sophisticated wind power forecasting tools associated a variety of meteorology input and their active integration into power-system operation are critical needed. Large numbers of methods for different applications have been developed based on various theories. Among these models, digital signal processing theory is playing a key role for data analysis, fitting and prediction. Although, until now, no perfect wind power forecasting tools are available, it is believed that associated with new technology, dramatic improvement will be accomplished.

\section{REFERENCES}

[1] W. Grant, D. Edelson, J. Dumas, J. Zack, M. Ahlstrom, J. Kehler, P. Storck, J. Lerner, K. Parks, and C. Finley, "Change in the air," IEEE Power Energy Mag., vol. 7, no. 6, pp. 47-58, Nov/Dec. 2009.

[2] T. Ackermann, G. Ancell, L. D. Borup, P. B. Eriksen, B. Ernst, F. Groome, M. Lange, C. Mohrlen, A. G. Orths, J. O'Sullivan, and M. de la Torre, "Where the wind blows," IEEE Power Energy Mag., vol. 7, no. 6, pp. 65-75, Nov/Doc. 2009.

[3] Photovoltaic Business in Germany- Status and Prospects: Annual report, 2008. [Online]. Available:http://www.iea-pvps.org/ar/ar08/germany.pdf.

[4] F. F. Wu, J. Zhong, and L. Zhang, "China's energy and environment," IEEE Power Energy Mag., vol. 4, no. 4, pp. 20-31, Jul./Aug. 2006.

[5] B. Ernst, B. Oakleaf, M. L. Ahlstrom, M. Lange, C. Moehrlen, B. Lange, U. Focken, and K. Rohrig, "Predicting the wind," IEEE Power Energy Mag., vol. 5, no. 6, pp. 78-89, Nov/Dec. 2007.

[6] NERC Special Report: Accommodating High Levels of Variable Generation, 2009. [Online]. Available:www.nerc.com.

[7] G. Giebel, P. Sørensen, and H. Holttinen, Forecast error of aggregated wind power, TradeWind Report, $2007 . \quad$ [Online]. Available:http://www.trade-wind.eu/fileadmin/documents/publications/D 2.2 Estimates_of forecast_error_for_aggregated_wind_power_Final.pdf.

[8] G. Sideratos and N. D. Hatziargyriou, "An advanced statistical method for wind power forecasting," IEEE Trans. Power Syst., vol. 22, no. 1, pp. 258-265, Feb. 2007.

[9] R. J. Bessa, V. Miranda, and J. Gama, "Entropy and correntropy against minimum square error in offline and online three-day ahead wind power forecasting," IEEE Trans. Power Syst., vol. 24, no. 4, pp. 1657-1666, Nov. 2009

[10]J. W. Taylor, P. E. McSharry, and R. Buizza, "Wind power density forecasting using ensemble predictions and time series models," IEEE Trans. Energy Conver, vol. 24, no. 3, pp. 775-782, Sept. 2009.

[11]H. Bludszuweit, J. A. Dominguez-Navarro, and A. Llombart, "Statistical analysis of wind power forecast error," IEEE Trans. Power Syst., vol. 23, no. 3, pp. 983-991, Aug. 2008.

[12]K. Methaprayoon, C. Yingvivatanapong, L. Wei-Jen, and J. R. Liao, "An integration of ANN wind power estimation into unit commitment 
considering the forecasting uncertainty," IEEE Trans. Ind. Appl., vol. 43, no. 6, pp. 1441-1448, Nov/Dec. 2007.

[13]T. H. M. El-Fouly, E. F. El-Saadany, and M. M. A. Salama, "Improved Grey predictor rolling models for wind power prediction," Generation, Transmission \& Distribution, IET, vol. 1, no. 6, pp. 928-937, Nov. 2007.

[14]C. W. Potter and M. Negnevitsky, "Very short-term wind forecasting for Tasmanian power generation," IEEE Trans. Power Syst., vol. 21, no. 2, pp. 965-972, May. 2006

[15]J. Matevosyan and L. Soder, "Minimization of imbalance cost trading wind power on the short-term power market," IEEE Trans. Power Syst., vol. 21, no. 3, pp. 1396-1404, Aug. 2006.

[16]A. Fabbri, T. GomezSanRoman, J. RivierAbbad, and V. H. MendezQuezada, "Assessment of the cost associated with wind generation prediction errors in a liberalized electricity market," IEEE Trans. Power Syst., vol. 20, no. 3, pp. 1440-1446, Aug. 2005

[17]G. N. Kariniotakis, G. S. Stavrakakis, and E. F. Nogaret, "Wind power forecasting using advanced neural networks models," IEEE Trans. Energy Conver, vol. 11, no. 4, pp. 762-767, Dec. 1996.

[18]J. Horstmann, H. Schiller, J. Schulz-Stellenfleth, and S. Lehner, "Global wind speed retrieval from SAR," IEEE Trans. Geosci. Remote Sens., vol. 41, no. 10, pp. 2277-2286, Oct. 2003.

[19]C. Surussavadee and D. H. Staelin, "Global millimeter-wave precipitation retrievals trained with a cloud-resolving numerical weather prediction model, part II: performance evaluation," IEEE Trans. Geosci. Remote Sens., vol. 46, no. 1, pp. 109-118, Jan. 2008.

[20]C. Surussavadee and D. H. Staelin, "Global millimeter-wave precipitation retrievals trained with a cloud-resolving numerical weather prediction model, part I: retrieval design," IEEE Trans. Geosci. Remote Sens., vol. 46, no. 1, pp. 99-108, Jan. 2008.

[21]S. J. English, B. Candy, A. Jupp, D. Bebbington, S. Smith, and A. Holt, "An evaluation of the potential of polarimetric radiometry for numerical weather prediction using QuikSCAT," IEEE Trans. Geosci. Remote Sens. vol. 44, no. 3, pp. 668-675, Mar. 2006.

[22]S. Lehner, J. Schulz-Stellenfleth, B. Schattler, H. Breit, and J. Horstmann, "Wind and wave measurements using complex ERS-2 SAR wave mode data," IEEE Trans. Geosci. Remote Sens., vol. 38, no. 5, pp. 2246-2257, Sept. 2000

[23]L. Isaksen and A. Stoffelen, "ERS scatterometer wind data impact on ECMWF's tropical cyclone forecasts," IEEE Trans. Geosci. Remote Sens., vol. 38 , no. 4, pp. 1885-1892, Jul. 2000.

[24]J. Figa and A. Stoffelen, "On the assimilation of Ku-band scatterometer winds for weather analysis and forecasting," IEEE Trans. Geosci. Remote Sens., vol. 38, no. 4, pp. 1893-1902, Jul. 2000.

[25]P. S. Chang and $\mathrm{L}$. $\mathrm{Li}$, "Ocean surface wind speed and direction retrievals from the SSM/I," IEEE Trans. Geosci. Remote Sens., vol. 36, no. 6, pp. 1866-1871, Nov. 1998.

[26]S. Brusch, S. Lehner, and J. Schulz-Stellenfleth, "Synergetic use of radar and optical satellite images to support severe storm prediction for offshore wind farming," Selected Topics in Applied Earth Observations and Remote Sensing, IEEE Journal of, vol. 1, no. 1, pp. 57-66, Mar. 2008.

[27]W.-Y. Tsai, S. V. Nghiem, J. N. Huddleston, M. W. Spencer, B. W. Stiles, and R. D. West, "Polarimetric scatterometry: a promising technique for improving ocean surface wind measurements from space," IEEE Trans. Geosci. Remote Sens., vol. 38, no. 4, pp. 1903-1921, Jul. 2000.

[28]C. R. Clauer, T. I. Gombosi, D. L. De Zeenw, A. J. Ridley, K. G. Powell, B. Van Leer, Q. F. Stout, C. P. T. Groth, and T. E. Holzer, "High performance computer methods applied to predictive space weather simulations," Plasma Science, IEEE Transactions on, vol. 28, no. 6, pp. 1931-1937, Dec. 2000.

[29]I. G. Damousis, M. C. Alexiadis, J. B. Theocharis, and P. S. Dokopoulos, "A fuzzy model for wind speed prediction and power generation in wind parks using spatial correlation," IEEE Trans. Energy Conver, vol. 19, no. 2, pp. 352-361, Jun. 2004.

[30]C. Nie and G. L. David, "A c-band wind/rain backscatter model," IEEE Trans. Geosci. Remote Sens., vol. 45, no. 3, pp. 621-631, Mar. 2007.

[31]T. G. Barbounis, J. B. Theocharis, M. C. Alexiadis, and P. S. Dokopoulos, "Long-term wind speed and power forecasting using local recurrent neural network models," IEEE Trans. Energy Conver, vol. 21, no. 1, pp. 273-284, Mar. 2006

[32]Ahlstrom, L. Jones, R. Zavadil, and W. Grant, "The future of wind forecasting and utility operations," IEEE Power Energy Mag., vol. 3, no. 6, pp. 57-64, Nov./Dec. 2005.

[33]M. D. Tsyroulnikov, "On the relative contribution of wind and mass observations in numerical weather forecasting," Dynam. Atmos. Oceans., vol. 37, no. 2, pp. 89-112, Aug. 2003.
[34]P. Beaucage, M. Bernier, G. Lafrance, and J. Choisnard, "Regional mapping of the offshore wind resource: towards a significant contribution from space-borne synthetic aperture radars," Selected Topics in Applied Earth Observations and Remote Sensing, IEEE Journal of, vol. 1, no. 1, pp. 48-56, Mar. 2008.

[35]B. C. Ummels, M. Gibescu, E. Pelgrum, W. L. Kling, and A. J. Brand, "Impacts of wind power on thermal generation unit commitment and dispatch," IEEE Trans. Energy Conver, vol. 22, no. 1, pp. 44-51, Mar. 2007.

[36]J. L. Torres, A. Garca, M. De Blas, and A. De Francisco, "Forecast of hourly average wind speed with ARMA models in Navarre (Spain)," Sol. Energy, vol. 79, no. 1, pp. 65-77, Jul. 2005.

[37]T. G. Barbounis and J. B. Theocharis, "Locally recurrent neural networks for wind speed prediction using spatial correlation," Inform. Sciences, vol. 177, no. 24, pp. 5775-5797, Dec. 2007.

[38]T. G. Barbounis and J. B. Theocharis, "Locally recurrent neural networks for long-term wind speed and power prediction," Neurocomputing, vol. 69, no. 4-6, pp. 466-496, Jan. 2006.

[39]R. G. Kavasseri and K. Seetharaman, "Day-ahead wind speed forecasting using f-ARIMA models," Renew. Energ., vol. 34, no. 5, pp. 1388-1393, May. 2009.

[40]R. L. McPherron, G. Siscoe, and N. Arge, "Probabilistic forecasting of the 3-h ap index," Plasma Science, IEEE Transactions on, vol. 32, no. 4, pp. 1425-1438, Aug. 2004.

[41]D. Vassiliadis, "System identification, modeling, and prediction for space weather environments," Plasma Science, IEEE Transactions on, vol. 28, no. 6, pp. 1944-1955, Dec. 2000.

[42]P. Louka, G. Galanis, N. Siebert, G. Kariniotakis, P. Katsafados, I. Pytharoulis, and G. Kallos, "Improvements in wind speed forecasts for wind power prediction purposes using Kalman filtering," $J$. Wind. Eng. Ind. Aerod, vol. 96, no. 12, pp. 2348-2362, Dec. 2008.

[43]M. Lange, "On the Uncertainty of Wind Power Predictions---Analysis of the Forecast Accuracy and Statistical Distribution of Errors," Journal of Solar Energy Engineering, vol. 127, no. 2, pp. 177-184, May. 2005.

[44]B. Venkatesh, Y. Peng, H. B. Gooi, and C. Dechen, "Fuzzy MILP unit commitment incorporating wind generators," IEEE Trans. Power Syst., vol. 23, no. 4, pp. 1738-1746, Nov. 2008.

[45]A. Dukpa, I. Duggal, B. Venkatesh, and L. Chang, "Optimal participation and risk mitigation of wind generators in an electricity market," Renewable Power Generation, IET, vol. 4, no. 2, pp. 165-175, Feb. 2010.

[46]A. Tuohy, P. Meibom, E. Denny, and M. O'Malley, "Unit commitment for systems with significant wind penetration," IEEE Trans. Power Syst., vol. 24, no. 2, pp. 592-601, May. 2009.

[47]J. Wang, M. Shahidehpour, and Z. Li, "Security-constrained unit commitment with volatile wind power generation," IEEE Trans. Power Syst., vol. 23, no. 3, pp. 1319-1327, Aug. 2008.

[48]J. Kennedy, B. Fox, and D. J. Morrow, "Distributed generation as a balancing resource for wind generation," Renewable Power Generation, IET, vol. 1, no. 3, pp. 167-174, Sept. 2007.

[49]M. A. Ortega-Vazquez and D. S. Kirschen, "Estimating the spinning reserve requirements in systems with significant wind power generation penetration," IEEE Trans. Power Syst., vol. 24, no. 1, pp. 114-124, Feb. 2009.

[50]L. Ruey-Hsun and L. Jian-Hao, "A fuzzy-optimization approach for generation scheduling with wind and solar energy systems," IEEE Trans. Power Syst., vol. 22, no. 4, pp. 1665-1674, Nov. 2007.

[51]L. Soder, "Reserve margin planning in a wind-hydro-thermal power system," IEEE Trans. Power Syst., vol. 8, no. 2, pp. 564-571, May. 1993.

[52]D. Corbus, D. Lew, G. Jordan, W. Winters, F. Van Hull, J. Manobianco, and B. Zavadil, "Up with wind," IEEE Power Energy Mag., vol. 7, no. 6, pp. 36-46, Nov./Dec. 2009.

Jin Zhong (M'2005) received the B. Sc. (Eng.) degree from Tsinghua University, Beijing, China, in 1995 and the M. Sc. (Eng.) degree from the Electric Power Research Institute, Beijing, in 1998, and the $\mathrm{Ph} . \mathrm{D}$ degree from Chalmers University of Technology, Gothenburg, Sweden, in 2003. She is an Assistant Professor in the Department of Electrical and Electronic Engineering at the University of Hong Kong.

Yunhe Hou (M' 06) received the B.E (1999), ME(2002) and Ph.D(2005) degrees from the Huazhong University of Science and Technology, China. He worked as a postdoctoral research fellow at Tsinghua University from 2005 to 2007. He was a visiting scholar at Iowa State University, Ames, and a researcher of University College Dublin, Ireland from 2008 to 2009. He is 
currently with the University of Hong Kong, Hong Kong, as a research assistant professor.

Felix F. Wu (M'74-F'89) is the Philip Wong Wilson Wong Professor in Electrical Engineering at the University of Hong Kong, Hong Kong, where he served as Pro Vice Chancellor (Vice President) from 1997 to 2001. He is also a Professor Emeritus at the University of California, Berkeley, where he has been on the Faculty since 1974. 